\title{
Desorption of SVOCs from Heated Surfaces in the Form of Ultrafine Particles
}

\author{
Wallace, Lance A.; Ott, Wayne R.; Weschler, Charles J.; Lai, Alvin C. K.
}

\section{Published in:}

Environmental Science and Technology

Link to article, DOI:

10.1021/acs.est.6b03248

Publication date:

2017

Document Version

Peer reviewed version

Link back to DTU Orbit

Citation (APA):

Wallace, L. A., Ott, W. R., Weschler, C. J., \& Lai, A. C. K. (2017). Desorption of SVOCs from Heated Surfaces in the Form of Ultrafine Particles. Environmental Science and Technology, 51(3), 1140-1146.

https://doi.org/10.1021/acs.est.6b03248

\section{General rights}

Copyright and moral rights for the publications made accessible in the public portal are retained by the authors and/or other copyright owners and it is a condition of accessing publications that users recognise and abide by the legal requirements associated with these rights.

- Users may download and print one copy of any publication from the public portal for the purpose of private study or research.

- You may not further distribute the material or use it for any profit-making activity or commercial gain

- You may freely distribute the URL identifying the publication in the public portal 


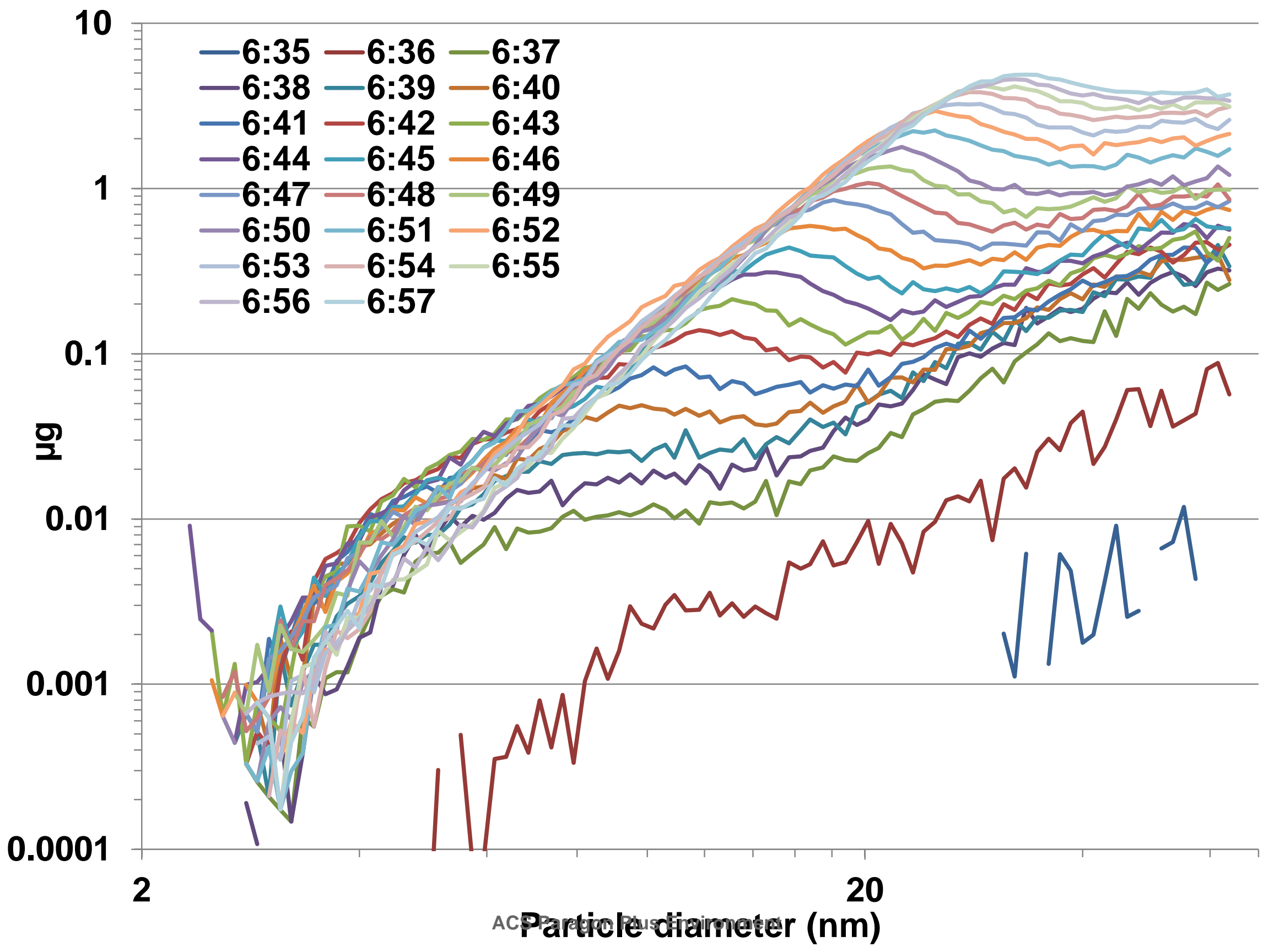


Desorption of SVOCs from heated surfaces in the form of ultrafine particles

6

9 Lance Wallace

10 US EPA (retired)

11 Affiliate, Lawrence Berkeley National Laboratory

12 Lwallace73@gmail.com

13

14

15 Wayne R. Ott

16 Stanford University

17 Dept. of Civil and Environmental Engineering

18

19

\section{Charles J. Weschler}

Environmental and Occupational Health Sciences Institute, Rutgers University, Piscataway, NJ

International Centre for Indoor Environment and Energy, Department of Civil Engineering, Technical University of Denmark, Lyngby, Denmark
Alvin C.K. Lai
Department of Architecture and Civil Engineering
City University of Hong Kong 
Abstract.

Ultrafine particles (UFP) produced by electric heating of stoves and metal cooking pans, absent food, have been hypothesized to be created from a surface film of semivolatile organic compounds (SVOCs) sorbed from the surrounding air. This study tests that hypothesis by size-resolved measurements extending the lower range of the UFP studied from $10 \mathrm{~nm}$ to $2.3 \mathrm{~nm}$, and including other surfaces (glass, aluminum, and porcelain). Heating glass Petri dishes or squares of aluminum foil to about $350-400{ }^{\circ} \mathrm{C}$ for 4-6 minutes removed all sorbed organic substances completely. Subsequent exposure of these "clean" Petri dishes and foil squares to indoor air in two different residences for successively longer periods (1 hour to 281 days), followed by heating the materials for 4-6 minutes, indicated a strong relationship of the number, size distribution, and mass of the UFP to the time exposed. Estimates of the accumulation rate of SVOCs on surfaces were similar to those in studies of organic film buildup on indoor windows. Transfer of skin oils by touching the glass or foil surfaces, or after washing the glass surface with detergent and bare hands, was also observed, with measured particle production comparable with that produced by longterm exposure to indoor air.

\section{Introduction.}

UFP in homes are produced by gas and electric stoves ${ }^{1-3}$, candles $^{4}$, toasters and toaster ovens ${ }^{5,6}$, steam irons $^{5}$, gas-powered clothes dryers ${ }^{7,8}$, and power tools ${ }^{9}$. Several sources of the particles have been identified. Combustion processes have been well studied as one source. Electric motors have been identified as sources of copper particles ${ }^{10}$. However, for electric stoves, toasters, toaster ovens, and steam irons, the source has not been definitively identified. In 2001, one research group suggested that for electric stoves the source might be the heating elements themselves or else dust or other material deposited on them ${ }^{1}$.

A recent study found that repeated reheating of an electric burner, three types of pans, and a steam iron with metal surface could eventually drive the particle production to zero, suggesting that the source was not the metal surface itself, but material deposited on the surfaces ${ }^{11}$. The authors also showed that the particle production was renewed after exposure for some days or weeks to indoor air, indicating that some substances in the air were collecting on the surfaces. They concluded that the source of the particles may have been a sorbed film of organic material derived from SVOCs found indoors ${ }^{12-14}$. It has been demonstrated that the equilibrium concentration of SVOCs in surface films can be estimated from an SVOC's octanol/air partition coefficient $\left(K_{o a}\right)$ and its gas phase concentration ${ }^{13}$. A simple calculation was employed to estimate the mass of SVOCs that would be deposited on surfaces over time and was consistent with the particle numbers observed. However, this previous study ${ }^{11}$ employed a condensation particle counter (CPC) sensitive only to particles $>10 \mathrm{~nm}$ and thus provided no indication of the number or mass size distribution or of the relative contribution of particles $<10 \mathrm{~nm}$ to the total particle production.

Therefore the present study was undertaken to extend these findings to different surfaces and to provide full size distributions including particle diameters from 2.3-160 nm. Also a closer study of the washing process was undertaken, including particularly a test of the possibility of contaminating the surfaces by the use of bare hands during washing. 


\section{Materials and Methods}

71

Three sites were included in the present study: private homes in Redwood City and Santa Rosa, CA and a laboratory at Hong Kong City University. In the main room in the Santa Rosa home, $\left(25.8 \mathrm{~m}^{3}\right.$ volume)(roughly 3 X 4 X $2 \mathrm{~m}$ ), the heating source was on the floor $\sim 1 \mathrm{~m}$ away from the North and East walls, with the aerosol intakes on a cart at a height $\sim 1 \mathrm{~m}$ and placed $\sim 1 \mathrm{~m}$ away from the center of the West wall. The straight-line distance from source to intake was $\sim 2 \mathrm{~m}$. Two oscillating fans were placed, one $\sim 1 \mathrm{~m}$ high near the SE corner of the room, and one on the floor near the center of the room. The Redwood City home used a $43 \mathrm{~m}^{3}$ room (roughly 4.5 X 3.2 X 3 m) with the aerosol intake of the Model 3007 placed $1.34 \mathrm{~m}$ from the heat source. A small electric fan was employed. In Hong Kong, selected experiments were performed within a $30 \mathrm{~m}^{3}$ chamber with controlled air exchange rates and including mixing fans.

A laboratory hot plate (Cimarec 1309HP15Q Digital Hot Plate, later replaced by Model HP88854100, http://www.mcqueenlabs.com/stir/cimarec-hp88854100.php was employed at the Santa Rosa and Redwood City sites to heat the Petri dishes, and at the Santa Rosa site only to heat the aluminum foil. For early experiments at the Redwood City site, a Proctor-Silex 1000-watt electric burner was used to heat a miniature stainless steel pan (DeBury) holding the Petri dishes. The Model 3007 CPC (TSI, Shoreview, $\mathrm{MN}$ ) used in our previous study ${ }^{1}$ was also used at all 3 sites. An SMPS with nano-DMA and a waterbased CPC (SMPS Model 3936, CPC model 3786, TSI, Inc. Shoreview, MN) was employed at Hong Kong, and an SMPS with nano-DMA and a water-based CPC (CPC model 3788) was used at Santa Rosa. The Hong Kong SMPS was operated at $15 \mathrm{Lpm}$ (sheath flow) and 1.5 Lpm (aerosol flow) providing a range from 2.3-65 nm; the Santa Rosa SMPS was operated with these settings but also at $30 \mathrm{Lpm}$ and 1.5 $\mathrm{Lpm}$, giving a nominal range from 1.5-44 nm; at $6 \mathrm{Lpm}$ and $0.6 \mathrm{Lpm}$, giving a range from 3.22 to 107 $\mathrm{nm}$; and at $3 \mathrm{Lpm}$ and $0.6 \mathrm{Lpm}$, giving a range from 4.6 to $160 \mathrm{~nm}$. (Since all CPCs used have an estimated $50 \%$ cutoff efficiency of about $2.5 \mathrm{~nm}$, the actual range over all configurations was only from 2.33-160 nm).

The surfaces tested included aluminum foil (www.reynoldsconsumerproducts.com), the porcelain hot plate mentioned above, and borosilicate (Pyrex) glass (55-mm and 100-mm Petri dishes, https://www.corning.com/).

A K-type thermocouple-based temperature probe (Fluke 51 thermometer equipped with Fluke 80PK-22 Immersion Temperature Probe; Fluke Corporation, www.fluke.com) was used to measure the temperature of the burner coils, the hot plate, and the metal and glass surfaces. Later a Fluke 54 II B with logging capability for two data channels and automatic data storage was employed. Partway through the study, it was found that the Fluke $80 \mathrm{PK}-22$ probe was underestimating surface temperatures; it was therefore replaced by two Thermoworks K-type surface probes (Models K-000 and K-020) with temperature ranges to $600{ }^{\circ} \mathrm{C}$ and $1000{ }^{\circ} \mathrm{C}$, respectively.

Sterile latex examination gloves (Dynarex) were employed for the washing experiments, along with sponges, nylon brushes, brushes with natural bristles, dishwashing detergents (Palmolive), cleansers (Barkeeper's Friend and Comet), and steel wool pads (SOS). The washing experiments focused on the miniature metal cooking pans used in our previous study and were carried out at all three sites. The related experiments involving aluminum foil pressed into these pans and touching the Petri dish surfaces were performed only at the Santa Rosa site. 
111 Data analysis. Aerosol Instrument Manager (AIM) proprietary software (TSI; AIM 10.0; later 10.2) was 112 used to determine size-resolved number concentrations. Because of the high diffusion coefficients of the 113 smaller UFPs, losses occur in the internal tubing of the classifier and the tubing connecting the classifier 114 to the CPC. Losses range from $<10 \%$ at the $40-60 \mathrm{~nm}$ range up to $>90 \%$ for particles $<2.6 \mathrm{~nm}$, according 115 to the manufacturer. Number concentrations were corrected for diffusion losses using Multi Instrument 116 Manager (v2.0; later 2.1) proprietary software (TSI). Temperature data from both the Fluke 51 and the 117 Thermoworks thermometers were obtained using Fluke proprietary software (Fluke View Forms, 118 v3.8.0003).

\section{Study design}

120 In the Santa Rosa home, a controlled experiment was conducted to estimate the rate of buildup of organic film on a borosilicate surface. Four dozen 55-mm Petri dishes (with 60-mm covers) were employed. All 96 Petri dish covers and bottoms were heated for 4-6 minutes to temperatures exceeding $300{ }^{\circ} \mathrm{C}$. They were then reheated to the same temperatures (repeatedly if necessary) to assure that no particles were produced. The "clean" Petri dishes were then arrayed (open sides up) on a clean surface consisting of freshly-unrolled aluminum foil (Reynolds Wrap). Other samples of aluminum foil from interior (unexposed) sections had been previously tested and found to produce no particles on initial heating. The Petri dishes or small squares of the aluminum foil were then exposed to indoor air for varying lengths of time (a few hours to 281 days). After exposure, the Petri dishes or aluminum foil squares were picked up with tongs and collected dust was blown off. They were then heated on the Cimarec laboratory hot plate for 4-6 minutes in the $25.8 \mathrm{~m}^{3}$ room with the floor fan on continually to promote good mixing. Total sizeresolved particle emissions and mass per unit surface area were then determined. Since the peaks were achieved generally within 1-2 minutes after the end of the heating period, a correction for deposition and air exchange during this short period was deemed unnecessary. To ensure that no organic material remained on the Petri dish after heating, it was allowed to cool and then reheated to the same temperature. In all cases, no or very few particles were produced, confirming that all material had been removed. An example of this procedure is provided in Figure S1 in Supporting Information. A total of 177 experiments (155 with Petri dishes, 22 with aluminum foil) were performed.

In the Redwood City home, the same approach as above was employed except that the particle counter was sensitive only to particles $>10 \mathrm{~nm}$. Early experiments used an electric burner (Proctor-Silex) to heat a miniature stainless steel pan repeatedly until both burner and pan were producing no particles. Then Petri dish covers or bottoms were heated in the pan as above following exposure to indoor air. Later experiments employed the Cimarec laboratory hot plate to heat the Petri dishes. 44 experiments spanning 1 to 207 days exposure were performed.

\section{Results and Discussion}

146 Quality Assurance. In the Santa Rosa home, the SMPS and Model 3007 were run side by side during all 147 experiments. A comparison of the SMPS results for particles $>10 \mathrm{~nm}$ agreed well with the Model 3007 148 results up to about $90,000 \mathrm{~cm}^{-3}$ (Figure S2 in Supporting Information). This is near the $100,000 \mathrm{~cm}^{-3}$ 149 value claimed by the manufacturers and confirmed in an independent study ${ }^{15}$. At higher concentrations, 
the Model 3007 suffers from particle obscuration in the sensing chamber, although correction algorithms ${ }^{15}$ can be applied to increase the range of useful measurement to about $300,000 \mathrm{~cm}^{-3}$.

In the Redwood City home, two Model 3007s were employed. One was new and had been recently calibrated by the manufacturer. The other was older and had not been recently calibrated. The two instruments were run side by side and showed very high correlations, but the older instrument readings averaged about $80 \%$ of those for the newer instrument. Therefore the experiments using the older instrument were corrected by a factor of 1.25 . Observed maximum concentrations exceeded $90,000 \mathrm{~cm}^{-3}$ on only two of 44 experiments and a correction using the algorithm ${ }^{15}$ would have been only a few percent so was not attempted.

Number and mass concentrations and total particle production. Background number concentrations indoors at Santa Rosa generally ranged from $100-3000 \mathrm{~cm}^{-3}$. Peak concentrations resulting from heating the metal, glass or porcelain surfaces averaged 186000 (SE 6000) $\mathrm{cm}^{-3}$ for particles $<10 \mathrm{~nm}$, and 124000 (7000) $\mathrm{cm}^{-3}$ for particles $>10 \mathrm{~nm}$. The total particles produced were in the range of $10^{12}$ to $10^{13}$, typically over a 4-6-minute heating period. The total mass produced, assuming a density of $1 \mathrm{~g} \mathrm{~cm}^{-3}$, ranged from $<1$ to $60 \mu \mathrm{g}$ in the $25.8 \mathrm{~m}^{3}$ room. The longer a surface was exposed to indoor air, in general, the higher the particle production when heated. The relationship may depend partly on intermittent activities such as cooking or baking in the home that contribute to the SVOCs that eventually coat the surfaces, or on temperature changes affecting the equilibrium between solid and gaseous phases, so a simple relationship cannot be expected. Also, air exchange with the outdoors continuously brings in different SVOC concentrations. However, assuming a roughly constant indoor gas-phase concentration for SVOCs, then a newly "clean" surface might display a number or mass per unit area accumulation $y(t)$ approaching an equilibrium concentration asymptote $a$ with an exponential time constant $\tau$, where $t$ is the amount of time exposed to indoor air:

$$
y(t)=a\left(1-\mathrm{e}^{(-t / \tau)}\right)
$$

At the Santa Rosa site, the characteristic time $\tau$ for particles $<65 \mathrm{~nm}$ per $\mathrm{cm}^{2}$ of heated surface was 11.7 (SE 1.2) days, with an estimated steady-state value of $0.35(0.01) \times 10^{12}$ particles $\mathrm{cm}^{-2}$ (Figure 1). Fitting the two surface types separately gave estimates for the characteristic time of 11.0 (1.2) days for the Petri dishes $(\mathrm{N}=155)$ and 13.5 (4.3) days for the aluminum foil $(\mathrm{N}=22)$. The estimated steady state values were also similar at $0.36(0.01) \times 10^{12}$ and $0.32(0.03) \times 10^{12}$ particles $\mathrm{cm}^{-2}$ for the Petri dishes and aluminum foil, respectively. 


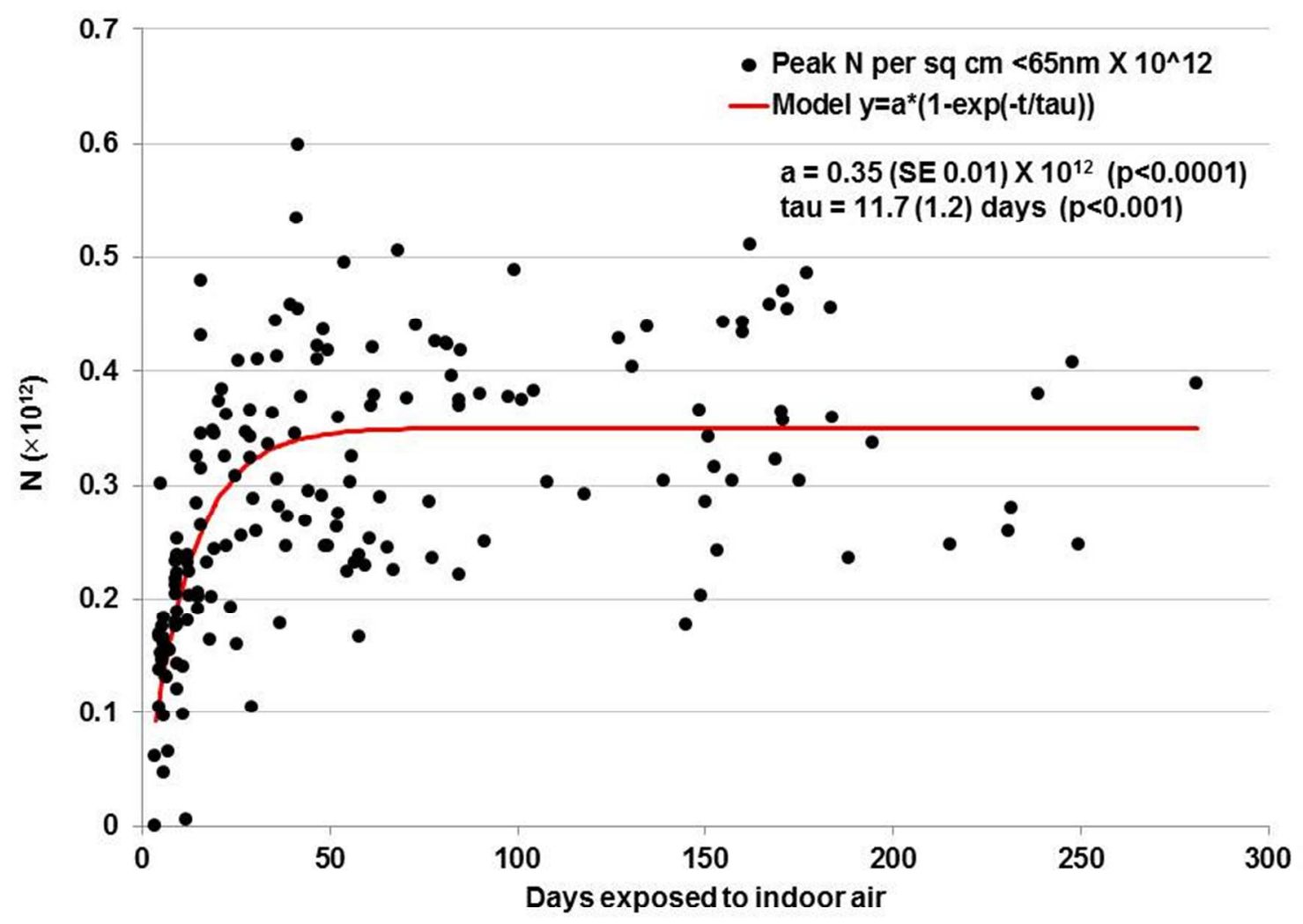

185 Figure 1. Number per $\mathrm{cm}^{2}$ of particles released during 4-6-minute heating periods of Petri dishes or aluminum foil exposed to room air for up to 281 days. Data from Santa Rosa site.

187

188 The model fit for the mass per unit surface area gave a much larger characteristic time of 132 (SE 35)

189 days (Figure 2). 


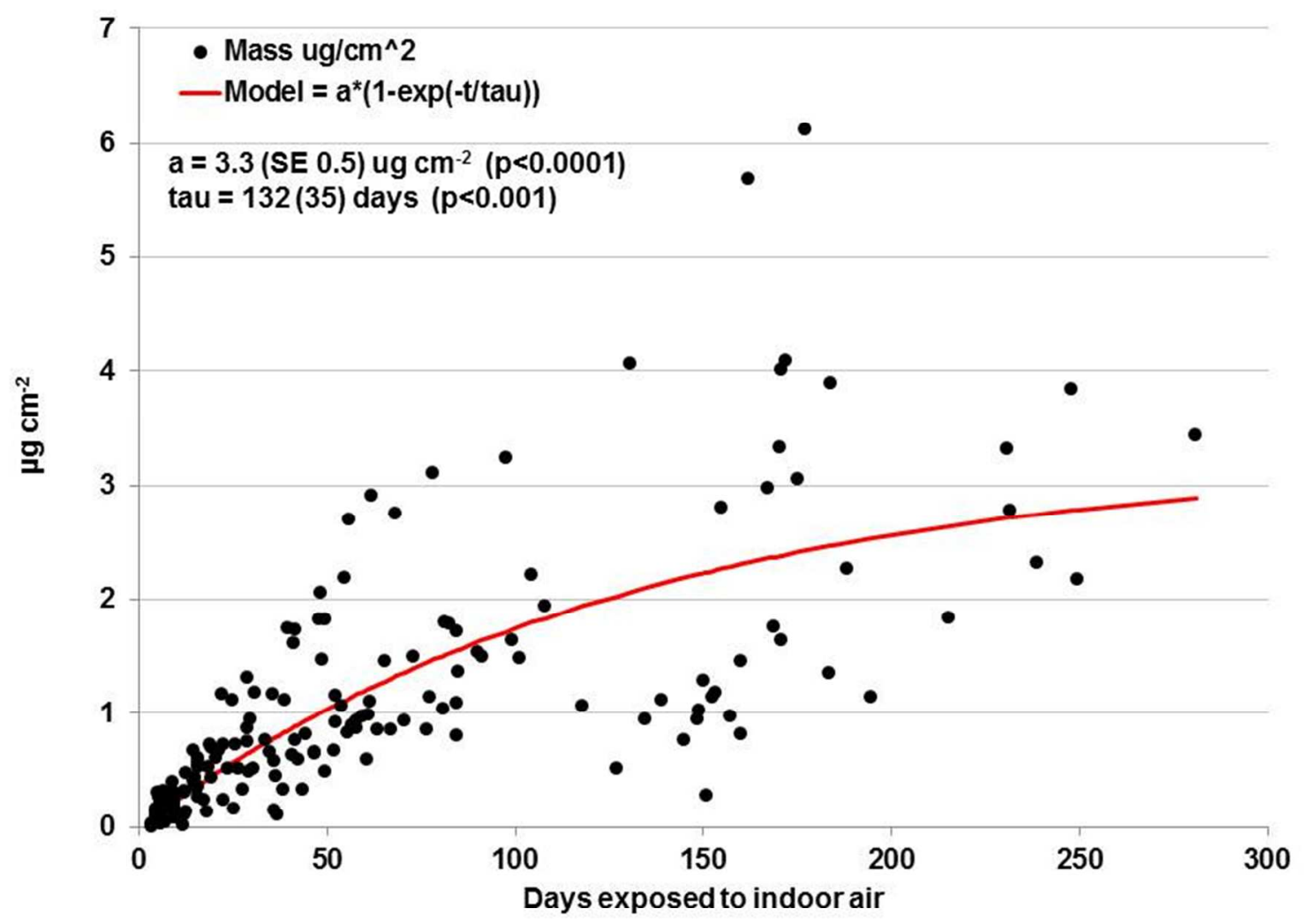

191 Figure 2. Mass per $\mathrm{cm}^{2}$ surface of particles released during 4-6-minute heating periods of Petri 192 dishes or aluminum foil exposed to room air for up to 281 days. Data from Santa Rosa site.

193 To estimate the rate of accumulation of mass, we can look at the period of the first 108 days when the 194 increase was nearly linear (Figure 3). The data for the Petri dishes and aluminum foil were analyzed 195 separately (black and green points and lines). The slopes of the lines, a measure of the rate of mass 196 buildup, were similar for the aluminum foil and Petri dishes, at about 0.017 and $0.019 \mu \mathrm{g} \mathrm{cm}^{-2}$ per day, 197 respectively. 


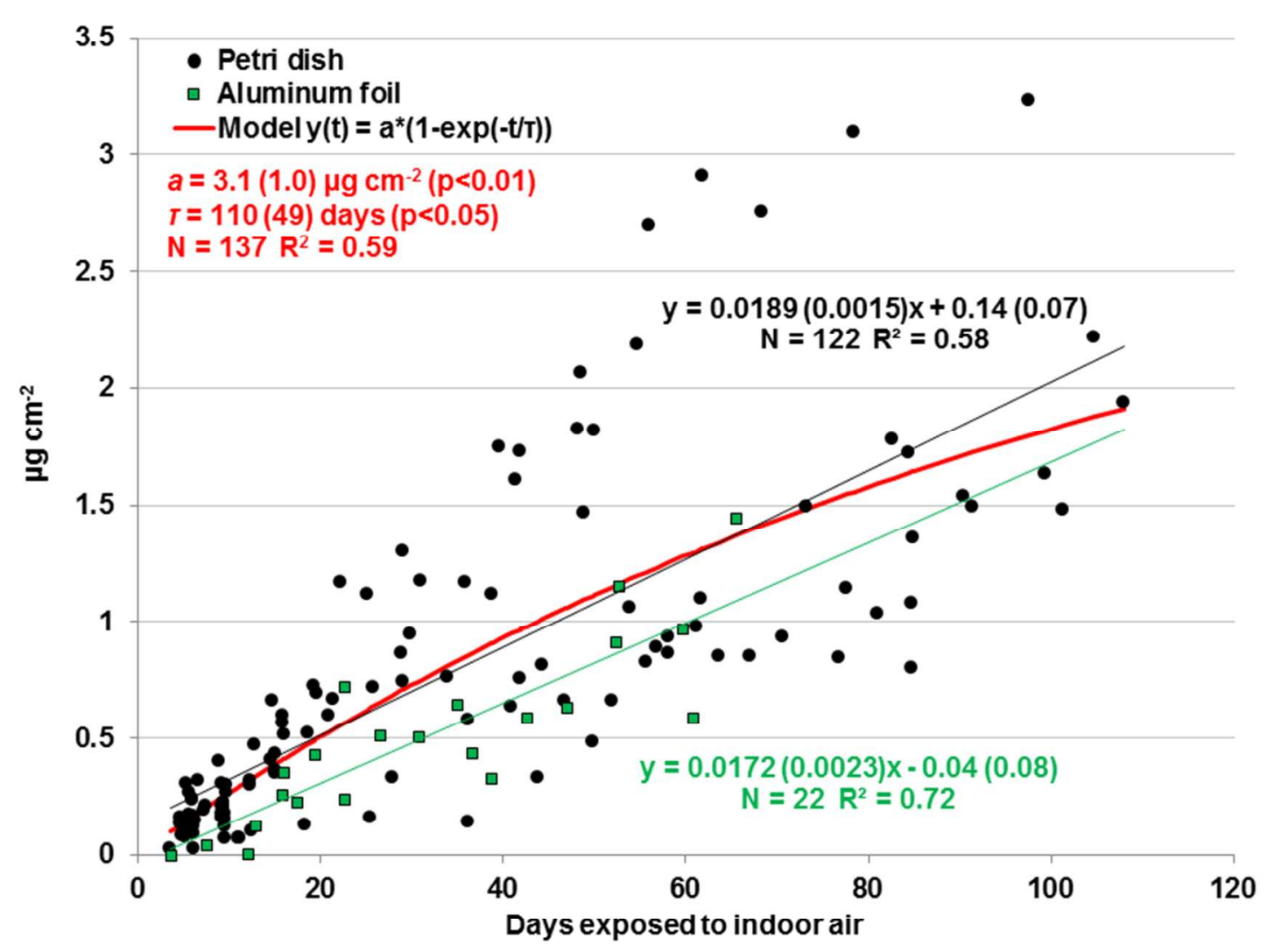

Figure 3. Mass per $\mathrm{cm}^{2}$ surface of particles released during 4-6-minute heating periods of Petri dishes or aluminum foil exposed to room air for up to 108 days. A 2-parameter fit (red curve) is performed on the full data set and is only barely significant. An ordinary least squares regression is performed on each of the two types of surfaces and is highly significant, with quite similar slopes (black and green lines). Data from Santa Rosa site.

The particle production and associated mass released for four size categories in each of these 177 experiments are provided in Table S1 (Excel file in Supporting Information). A summary of the experiments is provided in Tables S2 (Santa Rosa) and S3 (Redwood City).

With increasing time of exposure, the mass distribution shifted toward larger particles (Figures S3 and S4), whereas the number distribution held steady with a mode between 3 and $10 \mathrm{~nm}$ (Figure S5).

211 Although the number mode does not change over time, due to the preponderance of particles $<10 \mathrm{~nm}$ in

212 diameter, the fraction of particles in this size category does decrease sharply over time, dropping from 60-

$21390 \%$ of all particles in the first few weeks to 50-65\% from about 60-280 days exposed to indoor air

214 (Figure S6). 
215 An obvious question is why the particle number concentration (Figure 1) reaches steady-state so much faster than the particle mass concentration (Figure 2). At present, we cannot answer this question definitively, but suggest possible explanations that might be probed in future studies. When the exposure time has been only a few days, the number of particles is small, and there may be insufficient surface area on pre-existing particles to accommodate condensation of all the supersaturated vapors; nucleation is required to produce new particles for supersaturated vapors to condense into. As the exposure time increases, and we know from Figure S5 that more large particles are produced, there is more surface area available for condensation, and nucleation of new particles becomes decreasingly necessary to accommodate condensation of the supersaturated vapors. Another potential limiter to particle count concentration is coagulation. For low exposure duration, most particles are small and coagulation is limited. As the exposure time increases, larger particles become available for scavenging the smaller particles, and they do so with far greater efficiency according to the Fuchs correction ${ }^{16}$. At high coagulation rates, the lifetime of freshly formed particles is quite short, limiting their contribution to the total particle count. The number counts (usually $<100,000$ particles $/ \mathrm{cm}^{3}$ ) are lower than levels at which coagulation would be expected to occur ${ }^{16}$. However, these concentrations are measured in the room after thorough mixing. The actual count concentration in the plume where nucleation occurs is likely much higher.

The absorption of thermally desorbed mass to existing and freshly nucleated particles is an ongoing process. Regarding the mass mode shift to larger particles with additional exposure time for the Petri dishes and foils, we suggest that once the critical point has been reached where there is sufficient particulate surface area to accommodate condensation of all the supersaturated vapors, additional material that has sorbed to the Petri dish or foil surfaces, when thermally desorbed, condenses on the now sufficient particulate surface area. This continues particle growth and the shift of the mass mode to larger and larger particles.

The observation that the particle mass concentration does not attain steady-state over a period of 108 days (Figure 3) relates to the rate at which organics accumulate on the Petri dish or foil surfaces. We anticipate that absorption of organics in the surface film will continue to occur as long as there are SVOCs in the room air that are not in equilibrium with their levels in the film. Organics that have larger $K_{\text {oa }}$ values require more time to equilibrate than organics with smaller $K_{\mathrm{oa}}{ }^{12,17-19}$. The time required to reach an overall steady-state will be determined by the time required for less volatile SVOCs to equilibrate. We can roughly estimate such a time using equation 4.1 in Weschler and Nazaroff ${ }^{12}$, which states that the time scale for an individual organic to achieve equilibrium absorption, $\tau$, is given by $K_{o a}{ }^{*} X / v_{d}$, where $K_{o a}$ is its octanol-air partition coefficient, $X$ is the equivalent thickness of the organic portion of the film, and $v_{d}$ is the mass transfer coefficient from room air to the film. Table S4 provides a range of values for these three parameters. Both the residence time $\tau$ and $3 \times \tau$ (the time to reach $99 \%$ of the final steady state concentration) are calculated. Thicknesses for the organic portion of films have been estimated on different indoor surfaces and are in the range of 5 to $30 \mathrm{~nm}^{13,18,20}$. A reasonable range for $v_{d}$, for indoor SVOCs, indoor surfaces and typical near surface-airflows is from 2.5 to $4 \mathrm{~m} / \mathrm{h}^{12}$. The biggest uncertainty is the value to use for $K_{o a}$. Above a certain Koa, the gas-phase concentration of an SVOC is so low that its contribution to film growth is negligible ${ }^{21}$. Based on reported correlations between gas-phase concentrations and surface film concentrations for certain high $K_{\text {oa }}$ SVOCs ${ }^{13,19}$, we infer that the "critical $\log K_{o a}$ " likely lies in the range of 11 to 13 . To be more specific, it would take between 400 and 600 days for a gas-phase SVOC with a $\log K_{o a}$ of 12 to reach steady-state partitioning with a 10 to $15 \mathrm{~nm}$ thick 
organic film assuming a $v_{d}$ of $3 \mathrm{~m} / \mathrm{h}$. This estimation is consistent with the observation that it takes much longer for the particle mass concentration (Figure 2) to reach steady-state than the particle number concentration (Figure 1).

In some experiments, the temperature was ramped up slowly to determine at what temperature particles first appeared. In general, no particles were observed at temperatures below $150{ }^{\circ} \mathrm{C}$. Most particles were generated between 200 and $250^{\circ} \mathrm{C}$, although in some experiments particle generation was observed at temperatures above $300{ }^{\circ} \mathrm{C}$ (Figure S7).

There is remarkably good agreement between the rate at which organic mass accumulates on Petri dishes or foils, based on the measurements in Figure 3, and the rate at which organic mass accumulates on indoor windows based on measurements reported in several studies. For example, Figure 1 of Huo et al. ${ }^{18}$ shows total accumulation of film mass on freshly cleaned windows over a 49-day period in winter and a 77-day period in summer for two urban buildings in northeastern China. The total (organic and inorganic) accumulation rate is roughly 0.034 to $0.036 \mu \mathrm{g} \mathrm{cm}^{-2}$ per day. If we use the author's assumption that $50 \%$ of the film is organic material, this corresponds to growth rates for the organic portion of the film of 0.017 to $0.018 \mu \mathrm{g} \mathrm{cm}^{-2}$ per day compared to our measured growth of about 0.017 and $0.019 \mu \mathrm{g} \mathrm{cm}^{-2}$ per day for the aluminum foil and Petri dishes, respectively. Considering the many differences in SVOC sources and environmental parameters between the two studies, we acknowledge that this agreement exceeds the accuracy of the measurements. Li et al. ${ }^{22}$ report growth rates for the organic portion of window films of 0.008 to $0.063 \mu \mathrm{g} \mathrm{cm}^{-2}$ per day for north facing windows and 0.005 to $0.076 \mu \mathrm{g} \mathrm{cm}^{-2}$ per day for north facing windows for a building in Guangahou, China. A final example comes from one of the first studies to measure growth of indoor window films ${ }^{20}$. The films listed in Table 1 of that paper were reported to have been measured 3 to 5 months after cleaning the windows from targeted buildings in greater Toronto; calculated growth rates for the organic portion of the indoor films are 0.003 to $0.017 \mu \mathrm{g} \mathrm{cm}^{-2}$ per day.

We judge that the major source of organics in both the window films and the surface of the Petri dishes and foils is sorption from the gas-phase. The rate at which organic films grow on indoor windows, Petri dishes and foils precludes a dominant contribution from the deposition of airborne particles. Particles smaller than $2.5 \mu \mathrm{m}$ diameter are predicted to deposit at rates two to three orders of magnitude slower than the measured rates (see calculations in Supporting Information). Particles larger than $2.5 \mu \mathrm{m}$ are not expected to soil vertical window surfaces and are anticipated to have very low concentrations in the room used for the measurements reported here (due to the filters used in the home's air distribution system). A possible contributor to the organic material collecting on the Petri dish surface is skin flakes or clothing particles from the experimenters. We have confirmed by direct experiment that skin flakes can contribute to the particle number and mass, presumably due to thermal desorption of skin oils contained in the skin cells (Figures S8 and S9). However, we calculate in the SI that the mass from this source is a small fraction of that from room air. Since the dust was blown off the Petri dishes before heating, we expect that most of the skin flakes or clothing fibers were removed. However, for situations in which dust is not removed, as in the use of cooking pans, it is possible that the organic material contained in the dust could contribute substantially to the total airborne particle number or mass. We plan to investigate this possibility in future work.

Comparison with Redwood City site. The 44 experiments using Petri dishes at Redwood City employed only the Model 3007 particle counter sensitive to particles $>10 \mathrm{~nm}$. To compare with these observations, 
only particles $>10 \mathrm{~nm}$ as measured by the Santa Rosa SMPS were selected. The model parameters were very similar in the two homes, despite the many likely differences in SVOC sources and concentrations, temperature, relative humidity, etc. The asymptotic particle production levels per square $\mathrm{cm}$ of surface area were $0.168(0.005) \times 10^{12}$ and $0.148(0.009) \times 10^{12}$ in Santa Rosa and Redwood City, respectively. The characteristic times were 27.8 (2.6) days and 42.2 (7.3) days, respectively. Neither the asymptotic values nor the characteristic times were significantly different. The combined data $(\mathrm{N}=221)$ and overall model fit are provided in Figure 4.

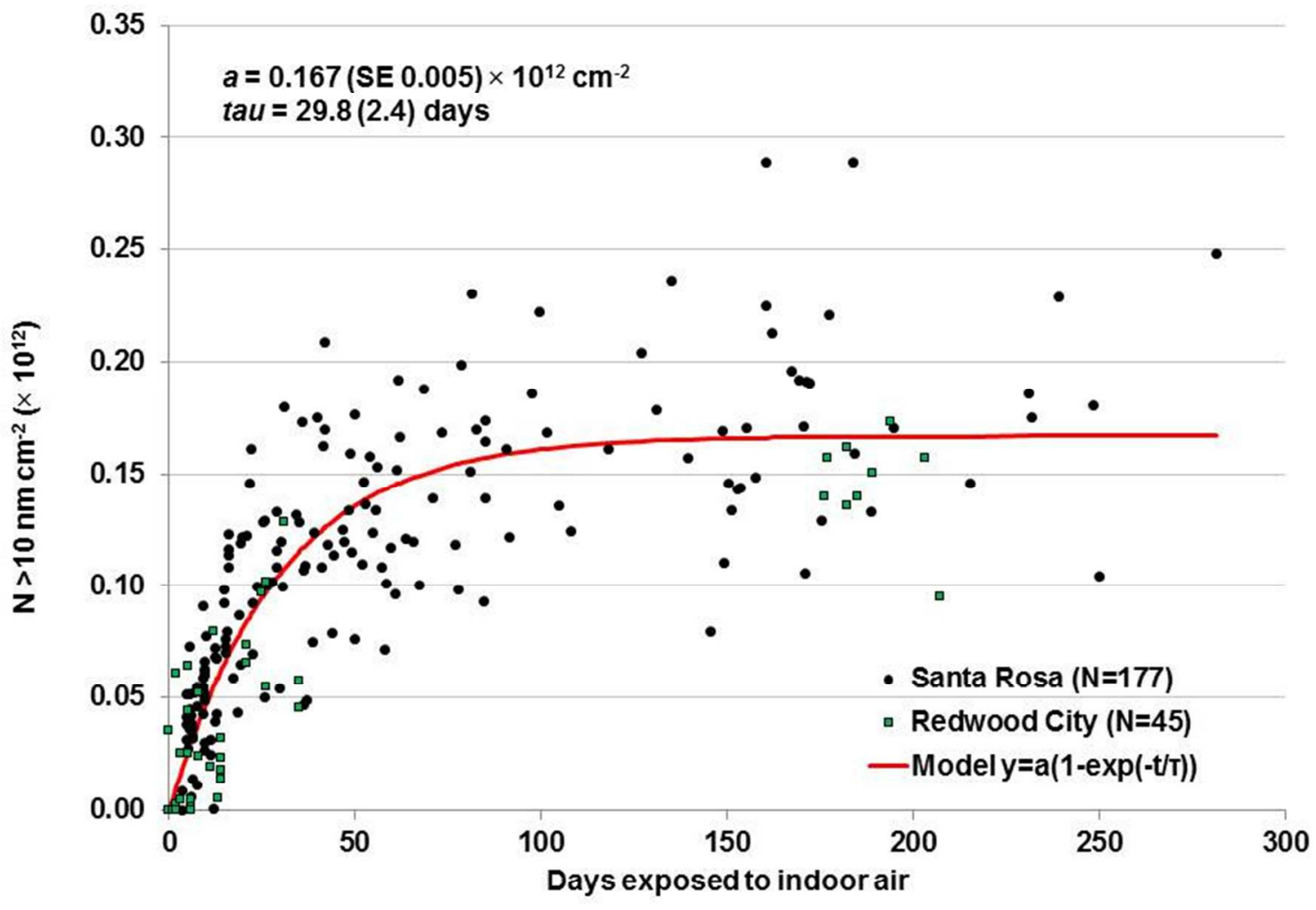

Figure 4. Particles $(>10 \mathrm{~nm})$ produced per square $\mathrm{cm}$ of surface area at Santa Rosa and Redwood

Contamination of surfaces by transfer of skin oil. As reported in our previous paper", "clean" pans (zero particle production) washed with detergent produced large numbers of particles on being heated. Those experiments and many of those described below employed the Model 3007 instrument with a lower size cutoff of $10 \mathrm{~nm}$. After May of 2015, the skin oil experiments employed the SMPS with a lower size cutoff of $2.33 \mathrm{~nm}$. Although at first we suspected the detergent might be the source of the particles, it was also possible that using our bare hands in the washing process may have contaminated the pans with skin oils even though the pans had been rinsed thoroughly. Therefore, we tried washing pans using sterile 
gloves. In 9 experiments washing the cast iron pans with detergent or other cleansers while wearing the gloves, 4 cases produced no particles at all, and the mean (SD) was only $4.5(5.2) \times 10^{10}$. By contrast, 29 experiments washing the cast iron pans with bare hands resulted in a mean (SD) particle production of 3.5 (3.0) $\times 10^{12}$, about 80 times as many. We conclude that transfer of skin oils while washing is the likely cause of the increased particle production following washing.

Aluminum foil is often used to line baking or roasting pans. Fish or poultry skin that would normally stick to the pans sticks instead to the foil, which can easily be disposed of, leaving a pan that is easy to clean. In 16 experiments, we used bare hands to tamp the foil down inside the miniature cast iron pans and then heated the pans. In another 8 experiments, we also used sterile gloves to tear off the foil and tamp it down in the pans before heating. In three more experiments, the experimenter washed his hands and sprayed them with isopropanol before tamping down the foil. The mean (SD) particle production after using bare hands to press down the foil and heating to temperatures ranging from $207-226^{\circ} \mathrm{C}$ was $1.1(1.2) \times 10^{12}$, compared to a mean (SD) of $3.8(9.0) \times 10^{11}$ after heating to temperatures of $207-223^{\circ} \mathrm{C}$ for the 11 experiments with either the sterile gloves or the clean hands. One of the experiments using the sterile gloves resulted in a particle production of $3.0 \times 10^{12}$, and was probably a case of contamination. The median value for these 11 experiments was not different from background levels, and the mean (SD) dropping the outlier was $1.1(1.3) \times 10^{11}$, a factor of 10 smaller than the mean of the experiments using bare hands.

We experimented with touching the cast iron pan directly. In four experiments, the experimenter touched the pan in a single spot on the bottom interior surface just after taking a shower. In all four experiments, no particles were observed after heating the pan to temperatures ranging from $193-202{ }^{\circ} \mathrm{C}$. In 7 experiments when no shower was taken, the pan was again touched by a thumb or finger; the mean particle production after heating to $145-202{ }^{\circ} \mathrm{C}$ was $2.0(0.9) \times 10^{12}$.

The results of 76 experiments addressing these three modes of possible contamination are summarized below (Table 1). The range of the mean number of particles produced for the three modes of skin oil transfer (1.1-3.5 $\left.\times 10^{12}\right)$ is comparable to the mean number of particles produced by 177 experiments with the Petri dishes and aluminum foil: $8.0(0.3) \times 10^{12}$ (Table S2).

\begin{tabular}{|c|c|c|c|c|c|c|}
\hline & Washir & g pan & Placin & g foil on pan & Touching & an directly \\
\hline & Bare hands & $\begin{array}{l}\text { Sterile } \\
\text { gloves }\end{array}$ & Bare hands & $\begin{array}{l}\text { Sterile gloves or } \\
\text { clean hands }\end{array}$ & Bare hands & $\begin{array}{l}\begin{array}{l}\text { Bare hands after } \\
\text { shower }\end{array} \\
\end{array}$ \\
\hline $\mathrm{N}$ & 29 & 9 & 16 & 11 & 7 & $\begin{array}{r}4 \\
\end{array}$ \\
\hline Mean & 3.50 & 0.04 & 1.14 & 0.38 & 1.98 & 0.00 \\
\hline SE & 0.57 & 0.02 & 0.30 & 0.27 & 0.35 & 0.00 \\
\hline
\end{tabular}

The concentrations observed after 4-6 minutes of heating in a room of volume $25.8 \mathrm{~m}^{3}$ are in the range of $10^{5}$ to $10^{6} \mathrm{~cm}^{-3}$, far higher than most values observed in ambient air even near high-traffic-density roadways. Although the smallest particles disappear within minutes, the remainder of the particles can remain at elevated concentrations for several hours. Therefore, we conclude that cooking and other operations involving heating surfaces to temperatures $>150{ }^{\circ} \mathrm{C}$ may have a substantial impact on total 
exposure to ultrafine particles. If the hypothesis is confirmed that most of these particles derive from SVOCs deposited on the surfaces, the findings suggest a newly appreciated pathway of exposure to SVOCs - inhalation of SVOCs liberated from heated surfaces. It appears that desorption of the material on surfaces that have previously been exposed to indoor air releases material from these surfaces, causing large quantities of airborne ultrafine particles to be produced.

Finally, we raise the possibility that a substantial portion of the UFP observed during cooking may arise from the release of SVOCs on the cooking surface, rather than arising from the cooking oil or food itself. Further study is indicated to determine whether this is indeed an important contributor to UFP observed during cooking.

\section{References}

1. Dennekamp, M.; Howarth, S.; Dick, C. A. J.; Cherrie, J. W.; Donaldson, K.; Seaton, A. Ultrafine particles and nitrogen oxides generated by gas and electric cooking. Occup. Environ. Med. 2001, 58, 511516.

2. Wallace, L.A.; Emmerich, S.J.; Howard-Reed, C. Source strengths of ultrafine and fine particles due to cooking with a gas stove. Environ. Sci. Tech. 2004, 38, 2304-2311.

3. Wallace, L.A.; Wang, F.; Howard-Reed, C.; Persily, A. Contribution of gas and electric stoves to residential ultrafine particle concentrations between $2 \mathrm{~nm}$ and $64 \mathrm{~nm}$ : size distributions and emission and coagulation rates. Environ. Sci. Technol. 2008, 42, 8641-8647.

4. Bekö, G.; Weschler, C.J.; Wierzbicka, A.; Karottki, D.G.; Toftum, J.; Loft, S.; Clausen, G. (2013) Ultrafine particles exposure and source apportionment in 56 Danish homes. Environ. Sci. Technol. 2013, 47, 10240-10248.

5. Schripp, T.; Kirsch, I.;Salthammer, T. Characterization of particle emission from household electrical appliances. Sci. Total Environ. 2011, 409, 2534-2540.

6. Wallace, L.A.; Ott, W.R. Personal exposure to ultrafine particles. J. Expo. Sci. Env. Epid. 2010, 21, 20-30.

7. Wallace, L.A. Ultrafine particles from a vented gas clothes dryer. Atmos. Environ. 2005, 39, 57775786.

8. Bhangar, S.; Mullen, N.A.; Hering, S.V.; Kreisberg, N.M.; Nazaroff, W.W. Ultrafine particle concentrations and exposures in seven residences in northern California. Indoor Air 2011, 21, 132-144.

9. Rim, D.; Green, M.; Wallace, L.A.; Persily, A.K.; Choi, J. Evolution of ultrafine particle size distributions following indoor episodic releases: relative importance of coagulation, deposition and ventilation. Aerosol Sci. Tech. 2012,46 (5), 494-503.

10. Szymczak, W.; Menzel, N.; Keck, L. Emission of ultrafine copper particles by universal motors controlled by phase angle. J. Aerosol Sci. 2007, 38(5), 520-531. 
11. Wallace, L.A.; Ott, W.R.; Weschler, C.J. Ultrafine particles from electric appliances and cooking pans: experiments suggesting desorption/nucleation of sorbed organics as the primary source. Indoor Air 2015, 25, 536-546.

12. Weschler, C.J.; Nazaroff, W.W. Semivolatile organic compounds in indoor environments. Atmos. Environ. 2008, 42, 9018-9040.

13. Weschler, C.J.; Nazaroff, W.W. SVOC exposure indoors: fresh look at dermal pathways. Indoor Air 2012, 22, 356-377.

14. Weschler, C.J. Indoor/outdoor connections exemplified by processes that depend on an organic compound's saturation vapor pressure, Atmos. Environ. 2003, 37, 5455-5465.

15. Hämeri, K.; Koponen, I.K.; Aalto, P.P.; Kulmala, M. The particle detection efficiency of the TSI-3007 condensation particle counter, J. Aerosol Sci. 2002, 33, 1463-1469.

16. Hinds, W. C., Aerosol Technology: Properties, Behavior, and Measurement of Airborne Particles, 2nd Edition, Wiley, 1999.

17. Pan, S.-H.; Li, J.; Lin, T.; Zhang, G.; Li, X.-D.; Yin, H., Polycyclic aromatic hydrocarbons on indoor/outdoor glass window surfaces in Guangzhou and Hong Kong, south China. Environmental Pollution 2012, 169, 190-195.

18. Huo, C.-Y.; Liu, L.-Y.; Zhang, Z.-F.; Ma, W.-L.; Song, W.-W.; Li, H.-L.; Li, W.-L.; Kannan, K.; Wu, Y.-K.; Han, Y.-M.; Peng, Z.-X.; Li, Y.-F., Phthalate Esters in Indoor Window Films in a Northeastern Chinese Urban Center: Film Growth and Implications for Human Exposure. Environ. Sci. Tech. 2016, 50, (14), 7743-7751.

19. Venier, M.; Audy, O.; Vojta, Š.; Bečanová, J.; Romanak, K.; Melymuk, L.; Krátká, M.; Kukučka, P.; Okeme, J.; Saini, A.; Diamond, M. L.; Klánová, J., Brominated flame retardants in the indoor environment - Comparative study of indoor contamination from three countries. Environment International 2016, 94, 150-160.

20. Liu, Q. T.; Chen, R.; McCarry, B. E.; Diamond, M. L.; Bahavar, B., Characterization of polar organic compounds in the organic film on indoor and outdoor glass windows. Environ. Sci. Technol. 2003, 37, (11), 2340-2349.

21. Pankow, J. F., An absorption model of gas/particle partitioning of organic compounds in the atmosphere. Atmos. Environ. 1994, 28, (2), 185-188.

22. Li, J.; Lin, T.; Pan, S.-H.; Xu, Y.; Liu, X.; Zhang, C.; Li, X.-D., Carbonaceous matter and PBDEs on indoor/outdoor glass window surfaces in Guangzhou and Hong Kong, South China. Atmos. Environ. 2010, 44, (27), 3254-3260.

Acknowledgements. Peter DeCarlo provided helpful comments regarding the number of particles produced by heating surfaces exposed for different time periods. Bill Nazaroff raised the possibility of skin flakes and particles from clothing adding to the SVOC loading on the Petri dishes. 